\title{
Correction to: Seed coating as a delivery system for the endophyte Trichoderma koningiopsis Th003 in rice (Oryza sativa)
}

\author{
Diego Cortés-Rojas ${ }^{1} \cdot$ Camilo Beltrán-Acosta ${ }^{2}$ - Yimmy Zapata-Narvaez ${ }^{2} \cdot$ Martha Chaparro $^{1} \cdot$ Martha Gómez $^{1}$. \\ Mauricio Cruz-Barrera ${ }^{1}$
}

Published online: 11 May 2021

(C) Springer-Verlag GmbH Germany, part of Springer Nature 2021

Correction to: Applied Microbiology and Biotechnology (2021) 105:1889-1904 https://doi.org/10.1007/s00253-021-11146-9

The published online version contains mistake.

The phrase "This work was carried out under the contract No. 168 of 2017 for access to genetic resources and derivates products in Colombia" should be introduced in the section Acknowledgements.

Publisher's note Springer Nature remains neutral with regard to jurisdictional claims in published maps and institutional affiliations.

The online version of the original article can be found at https://doi.org/ 10.1007/s00253-021-11146-9

Mauricio Cruz-Barrera

fcruz@agrosavia.co

1 Bioproducts Department, corporación colombiana de investigación agropecuaria (AGROSAVIA), Km 14 Bogotá-Mosquera, Mosquera, Colombia

2 Tibaitatá Research Center, corporación colombiana de investigación agropecuaria (AGROSAVIA), Km 14 Bogotá-Mosquera,

Mosquera, Colombia 